Patient journey mapping: Current practices, challenges and future opportunities in healthcare
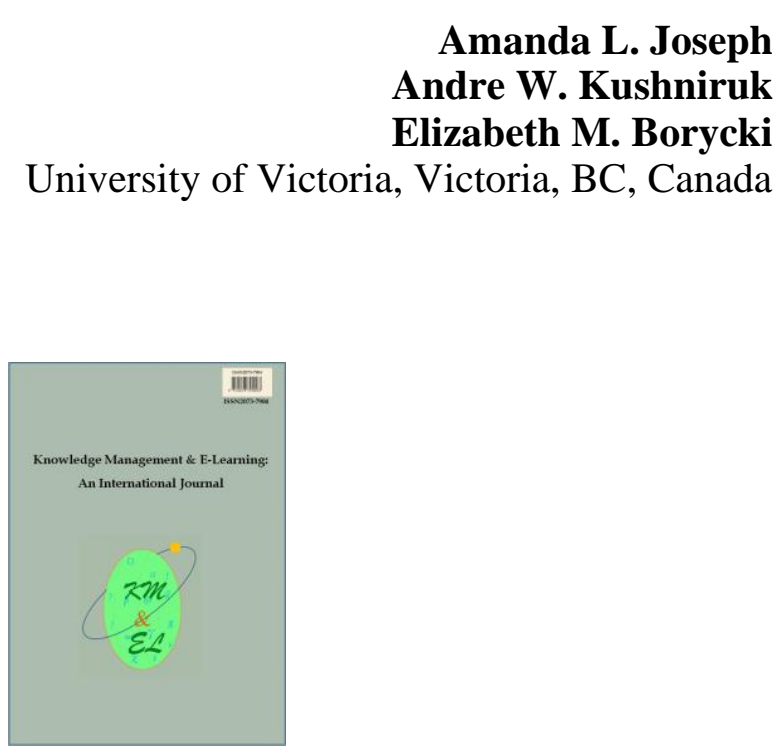

Knowledge Management \& E-Learning: An International Journal (KM\&EL) ISSN 2073-7904

Recommended citation:

Joseph, A. L., Kushniruk, A. W., \& Borycki, E. M. (2020). Patient journey mapping: Current practices, challenges and future opportunities in healthcare. Knowledge Management \& E-Learning, 12(4), 387-404. https://doi.org/10.34105/j.kmel.2020.12.021 


\title{
Patient journey mapping: Current practices, challenges and future opportunities in healthcare
}

\author{
Amanda L. Joseph*io \\ School of Health Information Science \\ University of Victoria, Victoria, BC, Canada \\ E-mail: amandalynnjoseph@uvic.ca
}

\author{
Andre W. Kushniruk \\ School of Health Information Science \\ University of Victoria, Victoria, BC, Canada \\ E-mail: andrek@uvic.ca
}

\section{Elizabeth M. Borycki}

School of Health Information Science

University of Victoria, Victoria, BC, Canada

E-mail: emb@uvic.ca

*Corresponding author

\begin{abstract}
Patient Journey Maps are an emerging concept that visually map each interactive touchpoint that the patient experiences as they navigate the care continuum. The purpose of this article is to: 1) Identify the ways that patient journey mapping has been used to identify efficiencies and inefficiencies in the healthcare process from a patient perspective, 2) Identify the type of approaches that have been documented to visually identify the patient journey, 3) Identify how information tools can be taken into account to improve gaps identified by patient journey mapping; and 4) Detail what patient journey visualization and mapping tools currently exist (and are used) in research and healthcare practice. A scoping review literature exploration, following the Arksey and O'Malley Framework (2005) was conducted in the PubMed database, with a focus on English publications only, using the search terms "patient journey map." Two researchers iteratively assessed the articles based on inclusion and exclusion criteria; 30 articles were included in the study. A thematic analysis was conducted and the findings were tabulated in the data extraction table. The patient journey map has considerable promise but continues to be an underutilized resource in industry - further research and standardization is required to increase adoption in the healthcare setting.
\end{abstract}

Keywords: Patient journey mapping; Healthcare journey map; Consumer health informatics; User experience; Visualization; Diagrams; Scoping review; Service delivery improvement

Biographical notes: Amanda Joseph is currently pursuing a Master of Science in Health Informatics at the School of Health Information Science at the University of Victoria in British Columbia, Canada. She has held leadership roles in the private, public and non-profit sectors of healthcare. Her research interests include process improvement in healthcare, patient safety, robotics, 
usability engineering and human factors (cognitive impacts of the patient, physician and caregiver journey). She has a pre-med background and graduated with distinction from Royal Roads University with a Bachelor of Commerce in Entrepreneurial Management.

Andre W. Kushniruk is Director and Professor in Health Informatics at the School of Health Information Science at the University of Victoria, Canada. He is a fellow of the American College of Medical Informatics. Dr. Kushniruk conducts research in a number of areas including usability engineering, humancomputer interaction in healthcare and cognitive studies of end users of health information systems. He has been involved in some of the first work in providing patients with internet access to their own health information (as stored in hospital-wide electronic health records) and he continues to work with designers and evaluators on a wide range of health information systems. $\mathrm{He}$ holds undergraduate degrees in Psychology and Biology from Brock University, as well as a MSc in Computer Science from McMaster University and a PhD in Cognitive Psychology from McGill University.

Elizabeth Borycki is a Professor in the School of Health Information Science at the University of Victoria, Canada. She is the Director of the Global Laboratory for Digital Health Innovation at the University of Victoria, Canada. Elizabeth conducts research at the intersection of safety science, human factors and technology in the field of health informatics. She is also a Clinician Scientist with the Michael Smith Foundation for Health Research, Vancouver, Canada. The Michael Smith Foundation for Health Research supports her research in this area of healthcare. Elizabeth's other research interests include safe health technology design, software engineering and implementation science involving health technology. Elizabeth is internationally recognized for her research having published over 200 peer-reviewed articles and ten edited books in the field of health informatics.

\section{Introduction}

Journey mapping has become a ubiquitous term and is quickly gaining notoriety in industry, as an effective visualization tool for strategic business initiatives and process improvement activities. "Journey maps evolved out of the service design field" (Howard, 2014 , p.12) and historically designers created them as blueprints to visually detail organizational processes or services. The design outputs of these blueprints were initially simple mapping visuals and flow charts, later evolving into the robust and diverse diagrams in use today (Howard, 2014). Journey maps present bidirectional workflow visualizations of organizational and consumer interactions, as each interactive touch point is detailed by the mapping exercise (Kalbach, 2016). The graphical nature of the diagrams serves as a visual conduit, allowing stakeholders to gain holistic perspectives, understand interconnected nuances of relationships and unearth organizational gaps. As a result of their effectiveness, there are many perceived benefits and opportunities for the advancement of journey mapping in industry and due to their emerging nature there is also a need for standardization.

\subsection{Different types of journey mapping}

Currently journey maps are not standardized in terms of terminology, diagram or intended use and consequently they are used and defined in a variety of contextual ways 
in industry. To simplify comparative analysis and provide consistency, the authors have defined the prominent five journey map diagram types in Table 1. Despite their nomenclative differences, each diagram provides a unique approach to documenting the consumer experience visually.

Table 1

Journey map diagrams (Kalbach, 2016)

\begin{tabular}{|c|c|c|c|}
\hline Diagram & Primary focus & Perspective & Display format \\
\hline $\begin{array}{l}\text { Customer } \\
\text { Journey }\end{array}$ & $\begin{array}{l}\text { Individual(s) end } \\
\text { to end experience }\end{array}$ & $\begin{array}{l}\text { Individual(s) are viewed as consumers of services or } \\
\text { products. It examines the relationship of individual as } \\
\text { a consumer of a particular service. }\end{array}$ & Chronological \\
\hline $\begin{array}{l}\text { Experience } \\
\text { Map }\end{array}$ & $\begin{array}{l}\text { Individual(s) end } \\
\text { to end human } \\
\text { experience }\end{array}$ & $\begin{array}{l}\text { Individual(s) activities are viewed broadly and aren't } \\
\text { organization specific and can involve a variety of } \\
\text { organizations. It examines the relationships of people } \\
\text { interacting with multiple products and services while } \\
\text { trying to satisfy their needs. }\end{array}$ & Chronological \\
\hline $\begin{array}{l}\text { Mental } \\
\text { Model } \\
\text { Diagram }\end{array}$ & $\begin{array}{l}\text { Individual(s) } \\
\text { cognitive } \\
\text { processes }\end{array}$ & $\begin{array}{l}\text { Individual(s) thought patterns and internal dialogue } \\
\text { are observed and can be applied to an organization or } \\
\text { event. It examines the way an individual perceives an } \\
\text { organization. }\end{array}$ & Hierarchical \\
\hline $\begin{array}{l}\text { Service } \\
\text { Blueprint }\end{array}$ & $\begin{array}{l}\text { Service } \\
\text { experience from a } \\
\text { systems view }\end{array}$ & $\begin{array}{l}\text { Individual(s) who receive a service. It examines } \\
\text { service processes, interactive touch points and service } \\
\text { overview. }\end{array}$ & Chronological \\
\hline Spatial Map & $\begin{array}{l}\text { Broad view of an } \\
\text { organization }\end{array}$ & $\begin{array}{l}\text { Individual(s) and organizational perspectives and } \\
\text { relationships are presented as models. It examines the } \\
\text { organization holistically. }\end{array}$ & Spatial \\
\hline
\end{tabular}

\subsection{Patient journey mapping in healthcare}

Despite being a frequently used method among service design engineers, the concept and use of patient journey mapping in the context of the healthcare sector is relatively novel. The "patient journey map provides a visual presentation of the complete route a patient follows during all stages of a care trajectory and the patients emotional experience during this journey" (Sijm-Eeken et al., 2020, p.1071). Fig. 1 presents a hypothetical scenario of the patient journey, using an Experience Map visualization style.

The patient journey mapping exercise is often performed utilizing data from a variety of sources including but not limited to: observations, questionnaires, semistructured interviews. The findings from these combined sources are documented and analyzed via a journey map diagram type (Table 1), resulting in holistic view of the patient experience. Much like the concept of the journey map, there are no standard approaches to performing the steps of the mapping exercise. The lack of consistent methodology may contribute to the low adoption rates in healthcare, as significant variation in diagram type does exist (Sijm-Eeken et al., 2020). 


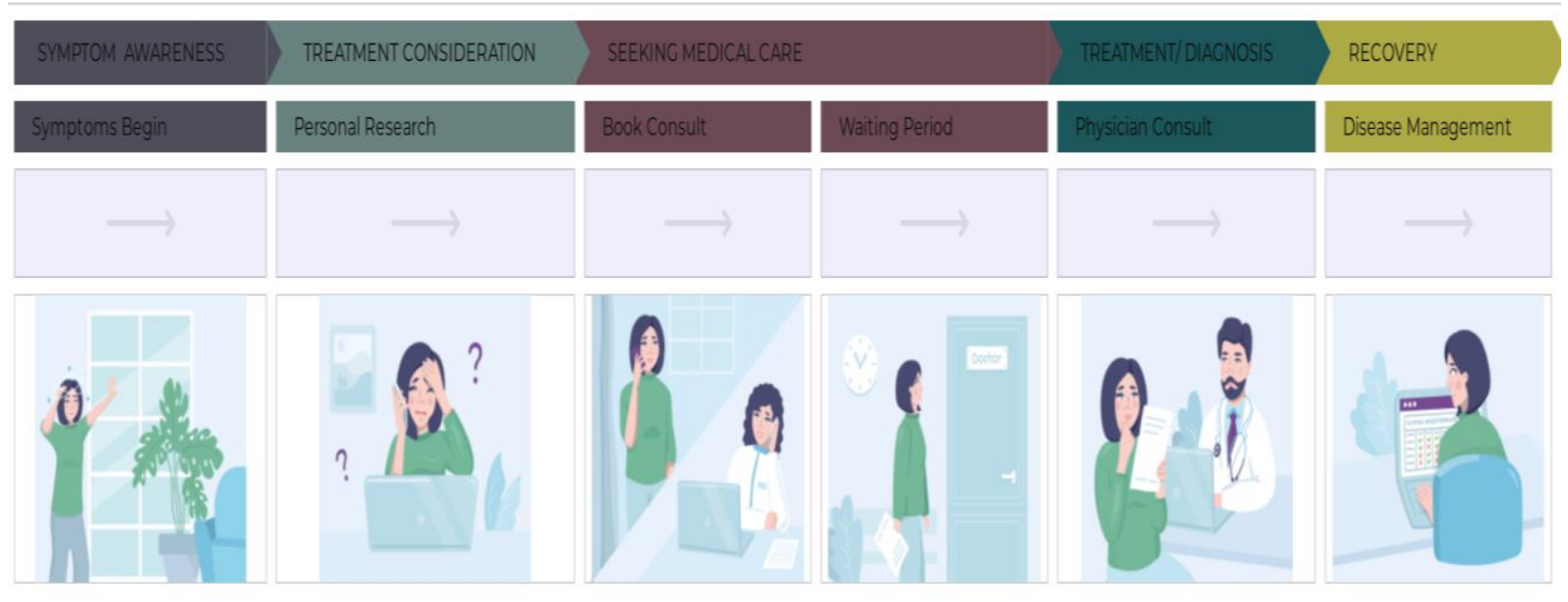

Fig. 1. Experience map visualization

\subsection{Factors that can empower the patient and improve their journey experience}

Providing Patients with timely unrestricted access to their health information, the concept of shared decision making (SDM) and the availability of health information on the internet all have tremendous potential to enrich the patient experience as will be described below.

\subsection{Providing patients with timely access to their health information}

There is an immediate need for patients to be provided with timely and relatable health information that they can easily access and understand. The idea of patients partnering with their care providers in a co-creative way shouldn't be perceived as a new concept. The feasibility of this partnership was demonstrated by the two studies conducted by Kushniruk and colleagues (Cimino et al., 1998, 2002) where the team developed a Patient Clinical Information System (PatCIS) to interface with the clinical data repository at New York Presbyterian Hospital (Cimino et al., 2002). PatCIS allowed patients to not only view, but also modify their health information (Cimino et al., 2002). The authors reported that no adverse events occurred, as a result of providing the patients with access to their health data. On the contrary, the findings indicated that providing patients with access to their health information, improved the patient and healthcare provider relationship during the patient journey "by allowing patients to review their data in detail prior to their actual visits, patients and physicians felt that the limited time available during the subsequent patient/physician interaction was used more efficiently, allowing for an enhanced level of discussion about the patient's problems and issues such as compliance" (Cimino et al., 2002, p.125).

\subsection{Access to health data without constraint}

Access to health data without constraint will become more vital, as healthcare technologies such as Electronic Health Records (EHRs), Personal Health Records (PHRs) and mobile health (mHealth) technologies continue to permeate the healthcare landscape. 
With increasing globalization, patients will require timely access to their health information without geographic or time zone impediments. To alleviate the constraints of inconsistent and fragmented access to health information, advances are being made on a global scale. To provide a single access point to healthcare services for both citizens and providers, a national e-Health portal (Sundhed.dk) was launched in Denmark in 2003 (Kushniruk \& Borycki, 2009). The Danish patient portal platform provides a positive patient journey experience and increases efficacy across the care continuum. That is, it enables citizens to use their own digital signature to log on to a personalized WebSpace to review their medication and healthcare data, communicate with healthcare authorities, book appointments, order medications and renew prescriptions (Kushniruk \& Borycki, 2009). These innovative works present vast opportunities for positively impacting the patient journey, improving safety and empowering patients to become active participants in their care (Borycki et al., 2012a, 2012b).

\subsection{Shared decision making and patient empowerment}

Patient journey maps are potentially another form of tool to support SDM and patient empowerment. Both concepts are symbiotic and have a mutually beneficial relationship. To empower a patient is to provide them with the opportunity to make a choice about whether or not to participate in their care trajectory alongside their care provider. In an article Eysenbach and Jadad (2001, p.2), describe "that (as long as they wish), all consumers should be able to access valid and relevant information about their health status." The authors further describe that patients "should be able to judge the advantages and disadvantages of all possible course of action, according to their values, beliefs, preferences, and their personal circumstances" (Eysenbach \& Jadad, 2001, p.2). Adopting a SDM and empowerment perspective could position both parties (patients and providers) as colleagues, sharing information in an ongoing dialogue and working together for shared positive patient outcomes. From this shared dialogue, the patient journey can be constructed in partnership and designed in unison. The clinicians in a study by Varpio et al. (2005, p.1019) described that "by consolidating and interpreting a wide array of patient data, building the patient's story was described as a vitally important skill that was required to provide patient - centered care, within an interprofessional team, that safeguards patient safety and clinicians' professional credibility."

\subsection{Quality health information available on the internet can potentially save lives}

Hospitals and healthcare facilities are increasingly becoming more complex, as they modify and transition from paper-based systems to electronic systems. Often clinical information is not accessible due to the siloed nature of information storage. It is not only difficult for care providers to access patient information in a timely and consistent fashion while providing care, but nearly impossible for the patients who want to become active participants in their care to access any of their clinical information. "The World Wide Web, a system composed of local browser software and Internet-based hypertext servers, addresses these issues elegantly.' Web browsers are available for most popular hardware and operating system platforms and provide access to a variety of servers on the internet" (Cimino et al., 1995).

"The internet holds the potential promise of improved patient outcomes, especially when one is faced with a critical or life-threatening disease or condition" (Kushniruk, 2019, p.1). In an article published in the Journal of Medical Internet 
Research, the author describes his own personal patient journey where the use of the internet not only facilitated a means for reaching a positive patient outcome, it saved his life (Kushniruk, 2019). This article also cautions that despite the plethora of readily consumable information available on the internet, that there are still "many human and technical barriers that may prevent the application of the best possible information for both patient and provider alike, making the patient journey complex and potentially dangerous" (Kushniruk, 2019, p.1). This journey illustrates the importance of humanrelated factors affecting access to health information" (Kushniruk, 2019, p.1). The aforementioned scenario also illustrates the dangers that fragmented health systems can pose and the difficulty patients can face when seeking care across the continuum. Utilizing a journey map diagram type (Table 1) to visually depict the authors experience would have efficiently revealed where the interruptions in healthcare service delivery occurred and how they could have been prevented. However, for the concept of patient journey mapping to gain industry traction and become common practice in healthcare settings, standardization of use, diagram type and the mapping exercise is paramount.

\subsection{Research objectives}

Now that patients are becoming more involved in their healthcare journey, new ways of documenting healthcare processes, identifying gaps and opportunities for improvement are necessary. Patient journey mapping may provide a powerful approach to characterizing and identifying patient interactions in order to identify ways of improving positive health outcomes and user satisfaction. This paper will address how patient journey mapping has or could be used for these objectives. Specifically, this paper will examine the following questions:

1. What are the ways that patient journey mapping has been used to identify efficiencies and inefficiencies in the healthcare process from a patient's perspective?

2. What type of approaches have been documented to visually identify the patient journey?

3. How can information tools be taken into account to improve gaps identified in the patient journey mapping?

4. What patient journey visualization and mapping tools currently exist (and are used) in research and healthcare practice?

\section{Methods}

A scoping review literature exploration, following the Arksey and O'Malley Framework (2005) was done in the PubMed database, using the search terms "patient journey map." All English articles that discussed methods for visually mapping the patient journey published between the years 2000 to 2020 were included for initial analysis. The date parameters were selected to reflect all available and relevant literature based on the search terms. The initial search was conducted by two researchers and yielded 61 articles. The two researchers then assessed the appropriateness of the initial search results by title and by reading the publication abstracts. If deemed relevant and applicable the researchers then read the articles in full and tabulated the visualizations in excel to conduct comparative analysis. This was an iterative process, as the articles were diverse in nature, spanned many countries and detailed various patient experiences around the globe. 


\subsection{Limitations}

Some limitations of the study include that the authors restricted their search strategy to only include the PubMed database. PubMed was deemed a sufficient database to use as an initial exploratory search, as many prominent health related articles are published and indexed within. Other relevant articles may have been excluded as a result of the search strategy and the English language preference. Due to the nature of scoping reviews the search strategy was broad and allowed for the inclusion of all relevant study types. The intent of the study was to have a diversified and robust complement of articles that discussed methods for visually mapping the patient journey. Inherent bias may also be present as the authors have extensive experience working in the healthcare sector. As this was a review of publicly available literature, the scoping review was exempt from a human research ethics review.

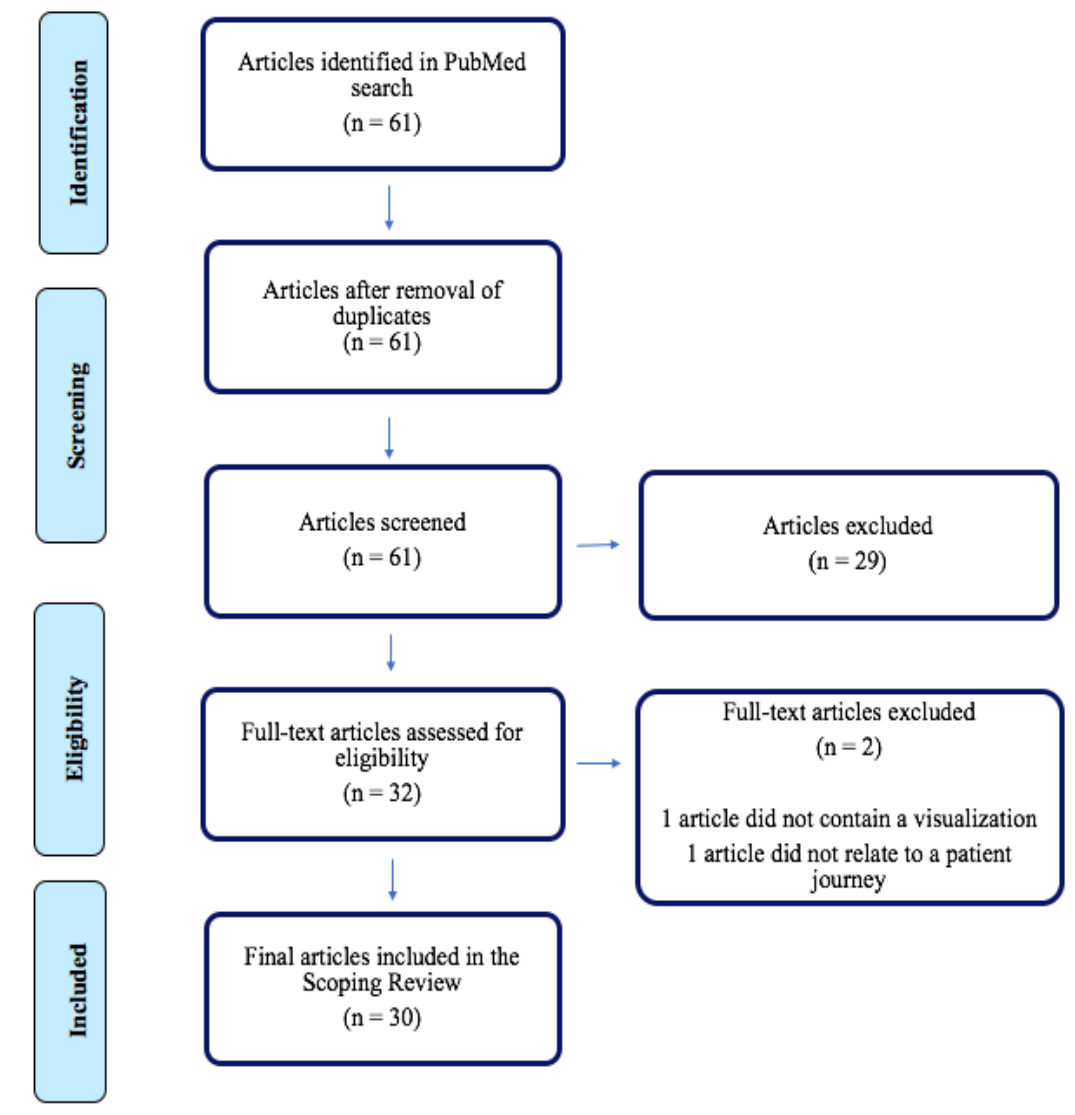

Fig. 2. PRISMA diagram. Adapted from PRISMA transparent reporting of systematic reviews and meta-analyses (2015)

\section{Results}

As detailed in the PRISMA Diagram (Fig. 2), the exclusion and inclusion process were iterative, the initial PubMed search yielded 61 results. The search did not yield any 
duplicate articles, therefore 61 articles were initially assessed for inclusion by title and abstract. From the first screen, a total of 29 articles were excluded as they did not contain visualizations of patient journey mapping. A full text review was then conducted and the remaining 32 articles were read in full, after analysis two articles were deemed irrelevant and were therefore excluded. One article was excluded as it did not contain an appropriate visualization related to patient journey mapping and a second was excluded as it did not describe the patient journey. A total of 30 articles were included in the scoping review, a thematic analysis was conducted and the findings were tabulated in the data extraction table (Table 2).

\subsection{Themes emerging from the included literature}

Although various themes were observed in the literature, the authors have created the below theme categories to simplify and allow for thematic comparative analysis. It must be noted that several other themes emerged in the literature and many of the noted themes were also presented throughout the other articles.

\subsection{Cognitive emotional aspects of the patient experience}

The cognitive and emotional aspects of the patient experience was a prominent theme that emerged throughout the literature. The patient journey is multifactorial and is influenced by not only the experience of navigating often complex health systems, but there are many psychological, psychosocial and physical elements to the way individuals cognitively process pain and illness. The below articles highlight the psychological and emotional components of the patient experience. The representation of patient journey mapping visualizations for this category varied and weren't homogeneous. However, as five articles utilized the Experience Map diagram and only one article utilized the Spatial Map diagram, there was a trend in Experience Map utilization.

In the article "Toward a model of continuous care: A necessity for caregiving partners" (Masterson et al., 2015) the authors mapped the lived experiences and emotional journey that caregivers face with disease progression and the death of a partner. Correlations between caregiving, pre-death and bereavement were also included in the mapping exercise (Masterson et al., 2015). Along a similar line, in the article entitled "Temporomandibular disorder patients' journey through care" (Durham et al., 2011) the authors mapped the patient journey and detailed that prior to seeking care, some individuals may experience psychological distress as a result of their illness. The authors also emphasized that interventions at specific interaction points in the patient journey could alleviate the distress experienced by patients (Durham et al., 2011). The article "Using Experience-Based Design to Improve the Care Experience for Patients With Pancreatic Cancer" (Hagensen et al., 2016) described the use of an experiencebased design methodology to map the patient journey and emotional experience as they navigate the health system during the course of their illness (Hagensen et al., 2016).

Castillo et al. (2013) in the paper entitled "A recovery journey for people with personality disorder" describe a study that illustrates the stages that people with personality disorder take in their recovery. The study was designed by the patient participants and offers a unique perspective into the psychological and psychosocial relationships of care and proposes a new model for the recovery journey (Castillo et al., 2013). Price and colleagues in the article "Initial assessment and management of pain: a pathway for care developed by the British Pain Society" (Price et al., 2014) detail the complexities and interrelationships of the psychological and physical aspects of the pain 
management journey. It is proposed that there could be correlations between levels of experienced pain, psychological issues and the introduction of new issues (Price et al., 2014). In the article "Cancer support services-are they appropriate and accessible for Indigenous cancer patients in Queensland, Australia?" (Whop et al., 2012) the authors examine the availability of cancer support services to Queensland residents and suggest that providing culturally appropriate cancer support services to Indigenous populations, may improve their healthcare experience, patient journey and reduce mortality rates (Whop et al., 2012).

\subsection{Identifying gaps in the healthcare process through journey mapping visualizations}

The literature exposed many gaps that exist in the health systems of many countries. Many healthcare service offerings were described as fragmented, inefficient and at times to even hinder care. Questions such as how to quantify the long-term impacts that a delayed cancer diagnosis, could pose to a patients lifespan arose. Along these lines, a number of articles highlighted how patient journey mapping could be used to identify gaps in key healthcare processes. The diagrammatical usage pattern in the literature was consistent and all articles utilized the Service Blueprint visualization style to represent the patient journey.

In the article "Towards a Lean Process for Patient Journey Mapping - A Case Study in a Large Academic Setting" (Sijm-Eeken et al., 2020) a study described and assessed the benefits of utilizing a lean process methodology to standardize the patient journey mapping exercise in an academic hospital (Sijm-Eeken et al., 2020). The mapping exercise described in the paper delineated the phases from initiation to data collection and mapping of the patient journey. A study described in the article "STEPS: lean thinking, theory of constraints and identifying bottlenecks in an emergency department" applied a lean thinking and theory of constraint processes to identify bottlenecks that occurred along the journey of emergency patients (Ryan et al., 2013). Evans and colleagues (2013) in the article "Improving the quality of lung cancer care in Ontario: the lung cancer disease pathway initiative" analyzed the quality of cancer care for lung patients across the continuum through the lens of the patient journey. Many organizational, process gaps were identified through this activity and by the mapping visualizations (Evans et al., 2013). Similarly, in the paper entitled "Development of an integrated and sustainable rural service for people with diabetes in the Scottish Highlands" Cramp (2006) described a regional review of current disparate diabetic care services throughout Scotland. The findings resulted in multidisciplinary collaboration and mapping activities which unearthed many gaps in service delivery (Cramp, 2006).

Jones et al. (2017) in the paper entitled "Synthesis maps: visual knowledge translation for the CanIMPACT clinical system and patient cancer journeys" two synthesis maps provide visualizations that describe critical differences between patient perspective and the clinical system. The intent of the visualizations was to display the interrelationships of the cancer patient experience and the cancer continuum (Jones et al., 2017). In the article "Identifying, Prioritizing and Visually Mapping Barriers to Injury Care in Rwanda: A Multi-disciplinary Stakeholder Exercise" Odland et al. (2020) undertook a comprehensive workshop series and conducted a scoping review, to establish the barriers to accessing quality care along the patient journey. The study unearthed many gaps and challenges which were visually represented by the complexities of the visualizations presented in the study. Additionally, in the article "Lung cancer patients' journey from first symptom to treatment: Results from a Greek registry" Kourlaba and 
colleagues (2019) describe a study that utilized hospital-based registry data of lung cancer patients to explore the impact that wait times, delayed diagnosis had on lung cancer mortality. The authors utilized Inversed Kaplan Meir Graphs to illustrate the time intervals of the patient journey (Kourlaba et al., 2019).

\subsection{Identifying the role of information technology in the patient care process}

Information technology is increasingly becoming more prominent in a healthcare context and when available, provides opportunity for improved healthcare administration and a better patient experience. However, one must be cognizant of the digital divide in that the successful deployment and sustainable access to healthcare technology is contingent on many factors; including but not limited to financial stability, infrastructure, internet, technological and healthcare literacy, privacy and security process establishment. The use of patient journey mapping visualizations was heterogeneous in this sample, two articles utilized the Service Blueprint style and two articles selected the Customer Journey Map diagram style.

The article "The Experiences of People Living with Peripheral Neuropathy in Kuwait-A Process Map of the Patient Journey" (Alkandari et al., 2019) highlighted the need for technological and administrative advancements in the healthcare sector, in particular primary and secondary care. The authors propose that a centralized electronic medical record (EMR) would improve data integrity and contribute to positive patient outcomes (Alkandari et al., 2019). Weir et al. (2018) in the paper entitled "Application of process mapping to understand integration of high-risk medicine care bundles within community pharmacy practice" describe a study that assessed community pharmacy processes and proposed a methodology that could mitigate future barriers of providing new services such as e-prescribing or automated dispensing (Weir et al., 2018). Pisaniello and Dixon (2020) in the article "What does digitalization hold for the creation of realworld evidence?" exemplify how a patient may seek help, guidance, support and information throughout their journey utilizing their own digital data. The research gap between journey maps and process mining and a new approach to digitize customer journey analysis is described in the article "Mapping the Patient's Journey in Healthcare through Process Mining" (Arias et al., 2020).

\subsection{Importance of shared decision making in care}

In the literature there was a general consensus that shared decision making (SDM) could improve the patient experience and empower the patient. It was also noted that all patients may not wish to be active participants in their care journey or discuss the specifics of their illness with their care providers. However, it was suggested that patients should still be provided the opportunity to participate in their care should they desire, not only as a respectful courtesy but also as a potentially important input to decision making. The articles in this section utilized a variety of visualization diagram types including: two Experience Maps, two Customer Journey Maps, two Service Blueprints.

Articles along this line included "Mapping the Patient Journey Across the Continuum: Lessons Learned from One Patient's Experience" (Meyer, 2019). The authors state that "patient experiences highlight the need for a shared, longitudinal care plan that clearly spells out the patient's health goal and serves as a roadmap to reach the best health outcome. This plan should be available electronically to all members of the care team including family members" (Meyer, 2019, p.105). In the paper entitled "The Hidradenitis suppurativa patient journey in Italy: current status, unmet needs and 
opportunities" (Bettoli et al., 2016) the need for continuous education for healthcare providers and patients was expressed. The authors also presented a multidisciplinary and collaborative approach to providing care, which could result in more efficient diagnostic and prognostic outcomes for the often-misdiagnosed disease (Bettoli et al., 2016). Selwood and colleagues (2017) in the article "Improving outcomes from high-risk surgery: a multimethod evaluation of a patient-centred advanced care planning intervention" examined the feasibility of incorporating SDM practices into the surgical workflow and proposed a new model of care. Under the new model, "clinicians will share responsibility for health outcomes with patients, and patients will only be admitted for surgery if it meets their goals and values better than alternative treatments" (Selwood et al., 2017, p.7).

In the article "Experiences of healthcare provision for foot ulceration occurring in people with rheumatoid arthritis" Firth et al. (2013) described that SDM should be a heavily leveraged modality of healthcare service delivery and that "more needs to be done to improve the continuity of care; patient involvement and communication between professionals, by using patient-held records or implementing agreed management plans"(Firth et al., 2013, p.166). Peng (2020) in the article "Applying normalization process theory and process mapping to understand implementation of a co-management program for older hip fracture patients in China: a qualitative study" described the various potential benefits of the co-management program such as increased communication between multidisciplinary teams and their patients. However, inconsistent care practices and provider burnout risks were identified as factors caused by increased workload on providers and workflow complexities that the program introduced (Peng, 2020). In considering the perspectives of stakeholders, in the article "Perspectives of Patients and Professionals on Information and Education After Myocardial Infarction With Insight for Mixed Reality Implementation: Cross-Sectional Interview Study" Hilt and colleagues (2020) carried out a study that highlighted conflicting opinions between care providers and patients in how they valued information and knowledge transfer, after myocardial infarction. The authors proposed that mixed reality could prove to be a future remedy to this issue (Hilt et al., 2020).

\subsection{Patient centric care can lead to positive health outcomes}

Like SDM, adopting a patient centric lens could lead to positive patient outcomes. Patient journey mapping could help emphasize the importance of this through visualizations. The journey mapping diagram usage varied, each author utilized diagrams to appropriate the intent of their article a little differently. The sample diagram findings include: one Customer Journey Map, three Service Blueprints, three Experience Maps.

Kuo et al. (2015) in the article "The rosacea patient journey: a novel approach to conceptualizing patient experiences" emphasized the importance of understanding the patient's perspective and how patient centric care can lead to positive outcomes. The journey of rosacea patients is largely behavioural, as patients can choose whether or not to seek care and continue their treatment regime (Kuo et al., 2015). The authors in the study entitled "Creation of a Patient-Centered Journey Map to Improve the Patient Experience: A Mixed Methods Approach" (Philpot et al., 2019) utilized mix methods to observe organizational processes, assess clinical care in a quality improvement lens to improve the patient care experience through human centered design (Philpot et al., 2019). Clark et al. (2019), in the article "Cardiotoxicity after cancer treatment: a process map of the patient treatment journey" describe the creation of a process map for cancer patients and detail that their findings "demonstrated that the clinical management of cancer 
patients with cardiotoxicity was variable and fragmented and not patient centered" (Clark et al., 2019, p.1).

The article "Evaluating the patient experience of an emergency burns assessment service in a UK burn unit using a service user evaluation questionnaire and process mapping" (Frew et al., 2020) was framed through a patient centric lens and was the first of its kind to assess the experience of burn injury patients from referral to assessment in an outpatient context (Frew et al., 2020). In considering variability among patients, in the paper entitled "Not a Straight Line-Patients' Experiences of Prostate Cancer and Their Journey Through the Healthcare System" Schildmeijer et al. (2019) emphasized that individualistic care is required and that each patient requires different levels of support, care and information throughout their journey. Along these lines, in the article "It Is a Life Journey: A Roadmap of Teens With Chronic Diseases in Transitioning to Independence" Sezgin et al. (2020) describes a study that assessed the life journey of adolescents with chronic disease and the interconnected relationships they have with their caregivers. The study also proposed that it may be beneficial to adopt a model of care that places importance on the personal archetypes, transition stages and life journey of patients (Sezgin et al., 2020). Finally, in the article "Priorities to improve the care for chronic conditions and multimorbidity: a survey of patients and stakeholders nested within the ComPaRe e-cohort" Tran and colleagues (2020) proposed " a new model to engage large numbers of patients in care improvement that can be replicated in other populations, contexts and countries (Tran et al., 2020, p.10). This article also emphasized that there may be a correlation for improved care when communication channels between the patient and clinician are open and consistent.

\subsection{Summation of thematic analysis}

The thematic analysis of the included literature can be summarized in the data extraction table found below (Table 2). As detailed in (Table 1) the five-principle journey map diagram types are: Experience Map, Spatial Map, Service Blueprint, Customer Journey Map, Mental Model Diagram. The data extraction table represents the full complement and diversity of the scoping review articles, journey mapping diagram types, study types, visualization types, the object(s) of the mapping exercise.

Table 2

Data extraction table

\begin{tabular}{|c|c|c|c|c|}
\hline Article, Author and Year & Journey Type & Study & Visualization Type & Object(s) of the mapping \\
\hline \multicolumn{5}{|c|}{ Theme 1: Cognitive emotional aspects of the patient experience } \\
\hline 1. Masterson et al., 2015 & Experience Map & Descriptive & Flow Chart & Caregivers \\
\hline 2. Durham et al., 2011 & Experience Map & Qualitative & Flow Chart & Patients with temporomandibular disorder \\
\hline 3. Hagensen et al., 2016 & Experience Map & Qualitative & Line Chart & $\begin{array}{l}\text { Patients with pancreatic cancer and their } \\
\text { caregivers }\end{array}$ \\
\hline 4. Castillo et al., 2013 & Experience Map & Exploratory & Pyramid Diagram & People diagnosed with personality disorder \\
\hline 5. Price et al., 2014 & Experience Map & Descriptive & Flow Chart & $\begin{array}{l}\text { Patients at risk of disability with complex } \\
\text { pain }\end{array}$ \\
\hline 6. Whop et al., 2012 & Spatial Map & Descriptive & Geographical Map & Indigenous cancer patients \\
\hline \multicolumn{5}{|c|}{ Theme 2: Identifying gaps in the healthcare process through journey mapping visualizations } \\
\hline 7. Sijm-Eeken et al., 2020 & Service Blueprint & Case Study & Swimlane Diagram & Patients \\
\hline 8. Evans et al., 2013 & Service Blueprint & Descriptive & Flow Chart & Lung cancer patients \\
\hline
\end{tabular}




\begin{tabular}{|c|c|c|c|c|}
\hline 9. Cramp, 2006 & Service Blueprint & Descriptive & $\begin{array}{l}\text { Flow Chart/ Service } \\
\text { level Map }\end{array}$ & People with diabetes \\
\hline 10. Jones et al., 2017 & Service Blueprint & Descriptive & Synthesis Map & Breast and colorectal cancer patients \\
\hline 11.Ryan et al., 2013 & Service Blueprint & Descriptive & Value Stream Map & Emergency department patients \\
\hline 12. Odland et al., 2020 & Service Blueprint & $\begin{array}{l}\text { Scoping Review/ } \\
\text { Workshop } \\
\text { Compilation }\end{array}$ & Connection Map & $\begin{array}{l}\text { Recipients of healthcare services in } \\
\text { Rwanda }\end{array}$ \\
\hline 13. Kourlaba et al., 2019 & Service Blueprint & Descriptive & $\begin{array}{l}\text { Inversed Kaplan } \\
\text { Meir Graph /Line } \\
\text { chart }\end{array}$ & Lung cancer patients \\
\hline
\end{tabular}

Theme 3: Identifying the role of information technology in the patient care process

\begin{tabular}{|c|c|c|c|c|c|c|}
\hline 14. Alkandari et al., 2019 & \multicolumn{2}{|c|}{ Service Blueprint } & \multicolumn{2}{|l|}{ Qualitative } & $\begin{array}{l}\text { Flow Chart/ Process } \\
\text { Map }\end{array}$ & $\begin{array}{l}\text { People living with peripheral neuropathy in } \\
\text { Kuwait }\end{array}$ \\
\hline 15. Weir et al., 2018 & \multicolumn{2}{|c|}{ Service Blueprint } & $\begin{array}{l}\text { Qualitative } \\
\text { Study }\end{array}$ & Case & $\begin{array}{l}\text { Flow Chart/Process } \\
\text { Map }\end{array}$ & Patients, pharmacists \\
\hline $\begin{array}{l}\text { 16. Pisaniello \& Dixon, } \\
2020\end{array}$ & $\begin{array}{l}\text { Customer } \\
\text { Map }\end{array}$ & Journey & Case Vignette & & Flow Chart & Patient with osteoarthritis \\
\hline 17. Arias et al., 2020 & $\begin{array}{l}\text { Customer } \\
\text { Map }\end{array}$ & Journey & Case Study & & $\begin{array}{l}\text { Flow Chart/ Process } \\
\text { Map }\end{array}$ & Patients \\
\hline
\end{tabular}

Theme 4: Importance of shared decision making in care
Case Report $\quad$ Timeline Chart $\quad$ Patients who need a hip replacement and

18. Meyer, 2019

Experience Map have multiple chronic conditions

19. Bettoli et al., 2016

Customer Journey

Descriptive

Flow Chart

20. Selwood et al., 2017

Service Blueprint

Feasibility

Evaluation

Flow Chart

Patients with hidradenitis suppurativa and healthcare providers

21. Firth et al., 2013

Experience Map

Qualitative

Flow Chart

High risk patients

22. Peng, 2020

23. Hilt et al., 2020

Service Blueprint

Qualitative

Flow Chart/Process

Patients with foot ulceration and rheumatoid arthritis

$\begin{array}{lll}\text { Customer } & \text { Journey } & \begin{array}{l}\text { Cross sectional } \\ \text { interview study }\end{array}\end{array}$

Map

Geriatric patients with hip fractures

Patients who have had a myocardial infarction

Theme 5: Patient centric care may can lead to positive health outcomes

\begin{tabular}{|c|c|c|c|c|}
\hline 24. Kuo et al., 2015 & $\begin{array}{l}\text { Customer Journey } \\
\text { Map }\end{array}$ & Descriptive & Flow Chart & Patients with rosacea \\
\hline 25. Philpot et al., 2019 & Service Blueprint & Mixed Methods & List Chart & Patients \\
\hline 26. Clark et al., 2019 & Service Blueprint & Mixed Methods & Flow Chart & $\begin{array}{l}\text { Patients who acquired cardiotoxicity } \\
\text { through the healthcare system }\end{array}$ \\
\hline 27. Frew et al., 2020 & Experience Map & $\begin{array}{l}\text { Service } \\
\text { Evaluation }\end{array}$ & List Chart & Patients with burn injuries \\
\hline $\begin{array}{l}\text { 28. Schildmeijer et al., } \\
2019\end{array}$ & Experience Map & $\begin{array}{l}\text { Qualitative, } \\
\text { Descriptive }\end{array}$ & Swimlane Diagram & Patients with prostate cancer \\
\hline 29. Sezgin et al., 2020 & Experience Map & Exploratory & Line Graph & $\begin{array}{l}\text { Adolescents with chronic disease and their } \\
\text { caregivers }\end{array}$ \\
\hline 30. Tran et al., 2020 & Service Blueprint & Exploratory & Scatterplot graphs & $\begin{array}{l}\text { Patients with chronic condition and } \\
\text { multimorbidity }\end{array}$ \\
\hline
\end{tabular}




\section{Discussion}

In this scoping review the authors reviewed 30 articles from the PubMed database, conducted a thematic analysis and tabulated the results in the data extraction table. As evidenced by this research, there is considerable potential for patient journey mapping to provide value in healthcare. This has ranges from a tool for identifying gaps, to understanding patient preferences and has real promise to revolutionize the healthcare industry by fundamentally changing the way that care is provided. However, as journey mapping visualizations lack standardization and consistency of use, there is much room for improvement in healthcare and future research is needed in many areas. The study introduced a set of four research questions which were examined in detail and the majority were resolved by the study findings, the unresolved aspects will contribute to future work that the authors are currently involved in. Patient journey mapping can be used to identify efficiencies and inefficiencies in healthcare processes. The research findings indicated that patient journey mapping is still an emerging concept that lacks standardization and nomenclative consistency. The included articles spanned many countries and provided a plethora of global examples of ways in which patient journey mapping visualizations could be utilized to identify service delivery gaps in the healthcare process from a patients perspective. However, due to low adoption rates and lack of standardization, patient journey maps remain an underutilized tool in the healthcare sector.

Several approaches were used to visually describe the patient journey. The articles included in the scoping review utilized four of the five stated journey mapping diagrams (Table 1): Experience Map, Spatial Map, Customer Journey Map, Service Blueprint. The Mental Model Diagram concept, as a mechanism for patient journey analysis was implied in the literature, however it was not visually represented as per the criteria detailed in Table 1. Despite Mental Model Diagrams not being explicitly identified in the literature, they hold considerable promise and provide a conduit into the psychological realm of human cognition. Understanding the patient's mental model, how they frame the reality of their own healthcare experience is paramount to the outcomes of their journey. The patient perspective could directly correlate to recovery times and mortality rates. The Mental Model mapping exercise could be conducted in a stages theory (Kübler-Ross, 2009) lens, utilizing the five common stages that an individual may passes through when faced with illness and/or their own fatality: 1) denial and isolation, 2) anger, 3) bargaining, 4) depression, 5) acceptance (Kübler-Ross, 2009). Understanding the patient's mental model as they pass through the continuum of care, could enable organizations and clinical stakeholders to understand why certain gaps may or may not hinder the patient experience more gravely than others. Having a deep appreciation for the complexities of the human psyche could enable journey mapping designer to assess clinical workflows, healthcare processes and interactions from a holistic patient centric lens. Viewing healthcare service delivery in the lens that every patient (and their provider) is uniquely experiencing several and often-concurrent journeys (e.g. illness, grief, life stage, personal circumstance) could lead to positive patient care outcomes, reduced provider burnout and increased empathy in healthcare settings.

The use of tools was limited in identifying gaps in patient care. The included literature did not provide a material tool list detailing how information tools could be taken into account to identify gaps in the patient journey mapping. However, as the concept of journey mapping and patient journey mapping specifically gain industry traction, new software tools could arise to simplify the manual process of transcribing observational findings, semi-structured interviews, questionnaires and aggregating source data. Visualization tools currently available in the marketplace may ameliorate and 
become more intuitive, incorporating such compliments as machine learning, artificial intelligence (AI) technologies and simulation modeling.

The question of what patient journey mapping visualizations and mapping tools exist in the marketplace, was not satisfied by the research. Journey maps and patient journey maps are used inconsistently and in many contextual ways in industry, as detailed in Table 1. Standardizing terminology, diagram type and use would provide a platform where new tools could emerge and gain industry prominence for patient quality and safety initiatives and a myriad of healthcare process improvement initiatives. Future research and standardization are needed in this area.

Once the benefit of patient journey mapping activities is realized, the potential for positive patient outcomes are endless. In addition to patient journey mapping, the concept of dual patient-healthcare provider experience mapping (Parush et al., 2014; Varpio et al., 2015) should also be further explored. The dual mapping exercise visually details the healthcare provider experience and interactions in parallel with those of the patient. Tremendous benefit could be realized by visually identifying the pain points and intersections of the physician and patient journey. Future research work that the authors are involved in includes exploring implementing patient journey maps using simulation software, conducting empirical studies that involve qualitative analysis of patient journey maps to identify varying patient experiences and potential for improving the health system. This could be used as feedback into a learning healthcare system (Friedman et al., 2010, 2015). Additionally, further reviews, such as the one described in this article could be conducted using other allied databases (e.g. in areas such as engineering and computer science) and conducted to evaluate how customer and user journey mapping has been applied in areas outside of healthcare.

\section{Conclusion}

In this paper we have seen a range of patient journey mapping uses, the possibilities for improving the healthcare system with its application is considerable. It can be concluded that published literature so far has indicated that patient journey mapping approaches hold significant promise, for understanding and improving complex healthcare process for patients and providers alike. Future work could include more closely integrating patient journey mapping into healthcare with the goal of creating a learning healthcare system.

\section{Author Statement}

The authors declare that they have no conflict of interest.

\section{ORCID}

Amanda L. Joseph (D) https://orcid.org/0000-0002-5869-037X

Andre W. Kushniruk (D) https://orcid.org/0000-0002-2557-9288

Elizabeth M. Borycki iD https://orcid.org/0000-0003-0928-8867 


\section{References}

Alkandari, M., Ryan, K., \& Hollywood, A. (2019). The experiences of people living with peripheral neuropathy in Kuwait-A process map of the patient journey. Pharmacy, 7(3): 127. doi: 10.3390/pharmacy7030127

Arias, M., Rojas, E., Aguirre, S., Cornejo, F., Munoz-Gama, J., Sepúlveda, M., \& Capurro, D. (2020). Mapping the patient's journey in healthcare through process mining. International Journal of Environmental Research and Public Health, 17(18): 6586. doi: 10.3390/ijerph17186586

Arksey, H., \& O'Malley, L. (2005). Scoping studies: Towards a methodological framework. International Journal of Social Research Methodology, 8(1), 19-32. doi: 10.1080/1364557032000119616

Bettoli, V., Pasquinucci, S., Caracciolo, S., Piccolo, D., Cazzaniga, S., Fantini, F., ... Naldi, L. (2016). The hidradenitis suppurativa patient journey in Italy: Current status, unmet needs and opportunities. Journal of the European Academy of Dermatology and Venereology, 30(11), 1965-1970. doi: 10.1111/jdv.13687

Borycki, E. M., Househ, M. S., Kushniruk, A. W., Nohr, C., \& Takeda, H. (2012a). Empowering patients: Making health information and systems safer for patients and the public. Yearbook of Medical Informatics, 7(1), 56-64.

Borycki, E. M., Kushniruk, A. W., Bellwood, P., \& Brender, J. (2012b). Technologyinduced errors: The current use of frameworks and models from the biomedical and life sciences literatures. Methods of Information in Medicine, 51(2), 95-103.

Castillo, H., Ramon, S., \& Morant, N. (2013). A recovery journey for people with personality disorder. International Journal of Social Psychiatry, 59(3), 264-273. doi: $10.1177 / 0020764013481891$

Cimino, J. J., Patel, V. L., \& Kushniruk, A. W. (2002). The patient clinical information system (PatCIS): Technical solutions for and experience with giving patients access to their electronic medical records. International Journal of Medical Informatics, 68(1/3), 113-127. doi: 10.1016/S1386-5056(02)00070-9

Cimino, J. J., Sengupta, S., Clayton, P. D., Patel, V. L., Kushniruk, A., \& Huang, X. (1998). Architecture for a web-based clinical information system that keeps the design open and the access closed. In Proceedings of the AMIA Symposium (pp. 121125).

Cimino, J. J., Socratous, S. A., \& Clayton, P. D. (1995). Internet as clinical information system: Application development using the world wide web. Journal of the American Medical Informatics Association, 2(5), 273-284. doi: 10.1136/jamia.1995.96073829

Clark, R. A., Marin, T. S., McCarthy, A. L., Bradley, J., Grover, S., Peters, R., ... Koczwara, B. (2019). Cardiotoxicity after cancer treatment: A process map of the patient treatment journey. Cardio-Oncology, 5: 14. doi: 10.1186/s40959-019-0046-5

Cramp, G. J. (2006). Development of an integrated and sustainable rural service for people with diabetes in the Scottish Highlands. Rural and Remote Health, 6: 422.

Durham, J., Steele, J., Moufti, M. A., Wassell, R., Robinson, P., \& Exley, C. (2011). Temporomandibular disorder patients' journey through care. Community Dentistry and Oral Epidemiology, 39(6), 532-541. doi: 10.1111/j.1600-0528.2011.00608.x

Evans, W. K., Ung, Y. C., Assouad, N., Chyjek, A., \& Sawka, C. (2013). Improving the quality of lung cancer care in Ontario: The lung cancer disease pathway initiative. Journal of Thoracic Oncology, 8(7), 876-882. doi: 10.1097/JTO.0b013e31828cb548

Eysenbach, G., \& Jadad, A. R. (2001). Evidence-based patient choice and consumer health informatics in the internet age. Journal of Medical Internet Research, 3(2): e19. doi: 10.2196/jmir.3.2.e19

Firth, J., Nelson, A., Briggs, M., \& Gorecki, C. (2013). Experiences of healthcare provision for foot ulceration occurring in people with rheumatoid arthritis. 
Musculoskeletal Care, 11(3), 159-167. doi: 10.1002/msc.1036

Frew, G. H., Abraham, I., Lancaster, D., Drake, P. J. H., \& Cassell, J. A. (2020). Evaluating the patient experience of an emergency burns assessment service in a UK burn unit using a service user evaluation questionnaire and process mapping. Burns, 46(5), 1066-1072. doi: 10.1016/j.burns.2019.11.004

Friedman, C., Rubin, J., Brown, J., Buntin, M., Corn, M., Etheredge, L., ... Van Houweling, D. (2015). Toward a science of learning systems: A research agenda for the high-functioning learning health system. Journal of the American Medical Informatics Association, 22(1), 43-50. doi: 10.1136/amiajnl-2014-002977

Friedman, C. P., Wong, A. K., \& Blumenthal, D. (2010). Achieving a nationwide learning health system. Science Translational Medicine, 2(57): 57CM29. doi: 10.1126/scitranslmed.3001456

Hagensen, A., London, A. E., Phillips, J. J., Helton, W. S., Picozzi, V. J., \& Blackmore, C. C. (2016). Using experience-based design to improve the care experience for patients with pancreatic cancer. Journal of Oncology Practice, 12(12), e1035-e1041.

Hilt, A. D., Mamaqi Kapllani, K., Hierck, B. P., Kemp, A. C., Albayrak, A., Melles, M., ... Scherptong, R. W. C. (2020). Perspectives of patients and professionals on information and education after myocardial infarction with insight for mixed reality implementation: Cross-sectional interview study. JMIR Human Factors, 7(2): e17147. doi: $10.2196 / 17147$

Howard, T. (2014). Journey mapping: A brief overview. Communication Design Quarterly Review, 2(3), 10-13. doi: 10.1145/2644448.2644451

Jones, P. H., Shakdher, S., \& Singh, P. (2017). Synthesis maps: Visual knowledge translation for the CanIMPACT clinical system and patient cancer journeys. Current Oncology, 24(2), 129-134. doi: 10.3747/co.24.3452

Kalbach, J. (2016). Mapping experiences: A guide to creating value through journeys, blueprints, and diagrams. New York, NY: O'Reilly Media.

Kübler-Ross, E. (2009). On death and dying (40th ed.). Abingdon, UK: Routledge.

Kuo, S., Huang, K. E., Davis, S. A., \& Feldman, S. R. (2015). The rosacea patient journey: A novel approach to conceptualizing patient experiences. Cutis, 95(1), 37-43.

Kourlaba, G., Gkiozos, I., Kokkotou, E., Stefanou, G., Papaspiliou, A., \& Syrigos, K. (2019). Lung cancer patients' journey from first symptom to treatment: Results from a Greek registry. Cancer Epidemiology, 60, 193-200. doi: 10.1016/j.canep.2019.04.014

Kushniruk, A. (2019). The importance of health information on the internet: How it saved my life and how it can save yours. Journal of Medical Internet Research, 21(10): e16690. doi: 10.2196/16690

Kushniruk, A., \& Borycki, E. (2009). Health information technology in Denmark: Forming the basis for an effective health information technology strategy. Healthcare Information Management \& Communications, 23(4), 42-43.

Masterson, M. P., Hurley, K. E., Zaider, T., \& Kissane, D. W. (2015). Toward a model of continuous care: A necessity for caregiving partners. Palliative \& Supportive Care, 13(5), 1459-1467. doi: 10.1017/S1478951515000231

Meyer, M. A. (2019). Mapping the patient journey across the continuum: Lessons learned from one Patient's experience. Journal of Patient Experience, 6(2), 103-107. doi: $10.1177 / 2374373518783763$

Odland, M. L., Whitaker, J., Nepogodiev, D., Aling', C. A., Bagahirwa, I., Dushime, T., ... Davies, J. (2020). Identifying, prioritizing and visually mapping barriers to injury care in Rwanda: A multi-disciplinary stakeholder exercise. World Journal of Surgery, 44(9), 2903-2918. doi: 10.1007/s00268-020-05571-6

Parush, A., Lourenco-Levin, M., \& Campbell, C. (2014). Dual patient-healthcare provider experience mapping and implications for information technology 
deployment and clinic layout. In Proceedings of the International Conference on Applied Human Factors and Ergonomics (pp. 389-396).

Peng, K., Liu, H., Zhang, J., Yang, M., Liu, Y., Tian, M., ... Ivers, R. (2020). Applying normalization process theory and process mapping to understand implementation of a co-management program for older hip fracture patients in china: A qualitative study. Archives of Osteoporosis, 15(1): 92. doi: 10.1007/s11657-020-00760-1

Philpot, L. M., Khokhar, B. A., DeZutter, M. A., Loftus, C. G., Stehr, H. I., Ramar, P., ... Ebbert, J. O. (2019). Creation of a patient-centered journey map to improve the patient experience: A mixed methods approach. Mayo Clinic Proceedings. Innovations, Quality \& Outcomes, 3(4), 466-475. doi: 10.1016/j.mayocpiqo.2019.07.004

Pisaniello, H. L., \& Dixon, W. G. (2020). What does digitalization hold for the creation of real-world evidence? Rheumatology, 59(1), 39-45. doi: 10.1093/rheumatology/kez068

Price, C., Lee, J., Taylor, A. M., \& Baranowski, A. P. (2014). Initial assessment and management of pain: A pathway for care developed by the British Pain Society. British Journal of Anaesthesi (BJA), 112(5), 816-823. doi: 10.1093/bja/aet589

PRISMA Transparent Reporting of Systematic Reviews and Meta-Analyses. (2015). PRISMA flow diagram. Retrieved from http://prismastatement.org/prismastatement/flowdiagram.aspx

Ryan, A., Hunter, K., Cunningham, K., Williams, J., O'Shea, H., Rooney, P., \& Hickey, F. (2013). STEPS: Lean thinking, theory of constraints and identifying bottlenecks in an emergency department. Irish Medical Journal, 106(4), 105-107.

Schildmeijer, K., Frykholm, O., Kneck, Å., \& Ekstedt, M. (2019). Not a straight linePatients' experiences of prostate cancer and their journey through the healthcare system. Cancer Nursing, 42(1), E36-E43. doi: 10.1097/NCC.0000000000000559

Selwood, A., Senthuran, S., Blakely, B., Lane, P., North, J., \& Clay-Williams, R. (2017). Improving outcomes from high-risk surgery: A multimethod evaluation of a patientcentred advanced care planning intervention. BMJ Open, 7(2): e014906. doi: 10.1136/bmjopen-2016-014906

Sezgin, E., Weiler, M., Weiler, A., Lin, S., \& Hart, L. (2020). It is a life journey: A roadmap of teens with chronic diseases in transitioning to independence. Journal of Pediatric Health Care, 34(4), 346-355. doi: 10.1016/j.pedhc.2020.02.001

Sijm-Eeken, M., Zheng, J., \& Peute, L. (2020). Towards a lean process for patient journey mapping - A case study in a large academic setting. Studies in Health Technology and Informatics, 270, 1071-1075.

Tran, V. T., Diard, E., \& Ravaud, P. (2020). Priorities to improve the care for chronic conditions and multimorbidity: A survey of patients and stakeholders nested within the ComPaRe e-cohort. BMJ Quality \& Safety. doi: 10.1136/bmjqs-2020-011219

Varpio, L., Rashotte, J., Day, K., King, J., Kuziemsky, C., \& Parush, A. (2015). The EHR and building the patient's story: A qualitative investigation of how EHR use obstructs a vital clinical activity. International Journal of Medical Informatics, 84(12), 10191028. doi: 10.1016/j.ijmedinf.2015.09.004

Weir, N. M., Newham, R., Corcoran, E. D., Ali Atallah Al-Gethami, A., Mohammed Abd Alridha, A., Bowie, P., ... Bennie, M. (2018). Application of process mapping to understand integration of high-risk medicine care bundles within community pharmacy practice. Research in Social and Administrative Pharmacy, 14(10), 944950. doi: 10.1016/j.sapharm.2017.11.009

Whop, L. J., Garvey, G., Lokuge, K., Mallitt, K. A., \& Valery, P. C. (2012). Cancer support services are they appropriate and accessible for indigenous cancer patients in Queensland, Australia? Rural and Remote Health, 12(3): 2018. 